American Journal of Animal and Veterinary Sciences 2 (1): 11-22, 2007

ISSN $1557-4555$

(C) 2007 Science Publications

\title{
Effects of Salmonella typhimurium Challenge on Swine Growth, Nitrogen Balance, Insulin-like Growth Factor-I, and Acute Phase Proteins
}

\author{
${ }^{1}$ Loughmiller, J. A., ${ }^{2}$ Dritz, S. S., ${ }^{1}$ Nelssen, J. L., ${ }^{1}$ Tokach, M. D., \\ ${ }^{1}$ Goodband, R. D., ${ }^{1}$ Moser, S. A., and ${ }^{1}$ De La Llata, M. \\ ${ }^{1}$ Department of Animal Sciences and Industry, Kansas State University, Manhattan 66506 \\ ${ }^{2}$ Food Animal Health and Management Center, Kansas State University, Manhattan 66506
}

\begin{abstract}
Growing barrows were used to determine the effects of an en teric disease challenge on nutrient balance, growth, acute phase proteins, and IGF-I. Pigs were challenged on $\mathrm{d} 0$ with Salmonella typhimurium (S; N=21), or unchallenged and fed ad libitum (A; $\mathrm{n}=6)$, or unchallenged and pair-fed the same amount of feed as a challenged pig $(P ; n=8)$. Blood was collected on $d-3,1,5,9$, and 15. A disease challenge $\times$ time interaction was observed for serum haptoglobin $(\mathrm{P}<0.05)$, with greater haptoglobin for $\mathrm{S}$ vs $\mathrm{A}$ on $\mathrm{d} 1$ and $5(\mathrm{P}<0.05)$ and for $\mathrm{S}$ vs $\mathrm{P}$ on d $5(\mathrm{P}<0.05)$. Plasma IGF-I increased from $\mathrm{d}-3$ to 17 (linear, $\mathrm{P}<0.05)$ and was increased for $\mathrm{S}$ vs $\mathrm{A}$ on $\mathrm{d} 9(\mathrm{P}<0.06)$ and $\mathrm{d} 15(\mathrm{P}$ $<0.03)$, and for $\mathrm{S}$ vs $\mathrm{P}(\mathrm{P}<0.02)$ on $\mathrm{d} 9$. A disease challenge $\times$ time interaction was observed $(\mathrm{P}<$ $0.05)$ for average daily gain as it decreased for $\mathrm{S}(.62 \mathrm{~kg})$ vs A $(1.38 \mathrm{~kg} ; \mathrm{P}<0.01)$ and $\mathrm{P}(.95 \mathrm{~kg} ; \mathrm{P}<$ $0.07)$ from $\mathrm{d} 0$ to 3 . A disease challenge $\times$ time interaction was observed for retained nitrogen $(\mathrm{N} ; \mathrm{P}<$ $0.05)$, indicating reduced lean growth from $\mathrm{d} 0$ to 3 for $\mathrm{S}(19.6 \mathrm{~g} / \mathrm{d} ; \mathrm{P}<0.01)$ and $\mathrm{P}(23.2 \mathrm{~g} / \mathrm{d} ; \mathrm{P}<$ $0.07)$ vs A $(30.1 \mathrm{~g} / \mathrm{d})$. Although short-term differences were evident, $\mathrm{d} 0$ to 17 growth performance and $\mathrm{N}$ balance were not affected by an acute $S$. typhimurium challenge $(\mathrm{P}>0.20)$. Results indicate that $66 \%$ of the short-term reductions in average daily gain from an acute S. typhimurium disease challenge are due to reductions in feed intake. The remaining differences are due to the acute phase immune response.
\end{abstract}

Key words: Pigs, N Balance, IGF-I, Acute Phase Proteins, Salmonella

\section{INTRODUCTION}

The effects of chronic disease challenges that restrict swine lean growth potential have been minimized by wide-scale adoption of all-in/all-out, multi-site production, and segregated early weaning ${ }^{[1,2]}$. However, short duration, acute disease challenges still occur in these high-health production systems. They usually result from a pathogen infecting immune-naive groups of pigs. The pathogen spreads rapidly throughout the group, and within a short period, immunity develops and performance partially recovers. Although lean growth rate has been improved dramatically in high-health production systems, acute disease challenges may be responsible for a large majority of the variation in lean growth rate between groups of pigs and among individuals within a group ${ }^{[3]}$.
Protein metabolism is negatively influenced in immune challenged pigs $^{[4,5]}$. However, these experiments either utilized a noninfectious challenge (LPS) or were designed to characterize chronic immune challenges typical in continuous flow production systems. Because acute disease challenges affect current production systems, determining their effects on growth performance and nitrogen $(\mathrm{N})$ balance should help industry professionals further understand the effects of an immune response in swine. Therefore, our objective was to characterize the effects of an acute enteric disease challenge in pigs by measuring changes in protein metabolism using $\mathrm{N}$ retention techniques. Furthermore, we wanted to document the changes in serum haptoglobin, alpha-1 acid glycoprotein (AGP), and plasma insulin-like growth factor I (IGF-I) concentrations before, during, and after an acute $S$. typhimurium infection.

Corresponding Author: $\quad$ Goodband, R.D., Kansas State University, Manhattan 66506, Tel: 785-6432-1228, FAX: 785-5327059 


\section{MATERIALS AND METHODS}

Animal Care and Use. This experimental protocol
was approved by the Kansas State University
Institutional Animal Care and Use Committee. Animals and Experimental Design. Thirty-five pigs (initially $32 \pm 1 \mathrm{~kg}$; PIC L326 $\times$ C22) free of clinical salmonellosis were obtained from the university herd and allotted to one of three experimental treatments. Pigs were selected monthly in groups of six to eight from the same weeks farrowing group, blocked by weight and time, individually housed, and randomly assigned to either the Salmonella typhimurium challenge treatment or one of two control treatments. The two control treatments consisted of pigs with either ad libitum access to feed, or to be pair-fed the net feed intake of an assigned S. typhimurium challenge pig. Because we expected greater variation in performance after the $S$. typhimurium challenge, 21 pigs were assigned to the S. typhimurium treatment, with 8 control pair-fed pigs, and 6 control ad libitum fed pigs.

Pigs assigned to the challenge treatment were inoculated intragastrically with doses of $3 \times 10^{9} \mathrm{cfu} S$. typhimurium in $4 \mathrm{~mL}$ culture media. Control pigs were treated similarly with $4 \mathrm{~mL}$ sterile media. This dosage of $S$. typhimurium previously to produced an acute immune response with minimal mortality ${ }^{[6,7]}$. Two $S$. typhimurium challenged pigs died during the course of this experiment, and are not included in the listed inventory of 21 S. typhimurium challenged pigs. They were necropsied at the Kansas State University Veterinary Diagnostic Laboratory, which determined that death likely resulted from an acute $S$. typhimurium challenge in both cases. All pigs that died were removed and are not included in the experiment. In addition, because one of the challenged pigs had a pair fed control assigned, both the challenge and pair fed pig were removed from the experiment. Only pigs that were alive on $\mathrm{d} 17$ were used in this experiment. Thus, 35 pigs completed the experiment.

Water was supplied at a 3.5:1 ratio with feed on a wt:wt basis ${ }^{[8]}$. All pigs were fed and watered twice daily at 0730 and $1930 \mathrm{~h}$. Orts were collected, dried, and weighed back daily. All pigs were fed a common corn-soybean meal diet formulated to contain $1.15 \%$ total lysine, with no crystalline amino acids, added fat, or antibiotics (Table 1). Five $4 \mathrm{~d}$ collection periods immediately followed a $3 \mathrm{~d}$ adjustment period (d -4 to 1,0 to 3,4 to 7,8 to 11 , and 14 to 17 ) with the $S$. typhimurium challenge occurring on $\mathrm{d} 0$. These times were selected to provide a prechallenge, challenge, two recovery periods, and a post recovery period. The final period was based upon a pilot study (data not reported) indicating that $14 \mathrm{~d}$ postchallenge was sufficient for complete recovery from a similar $S$. typhimurium challenge dose. All pigs were euthanized humanely on d 27 by intravenous sodium pentobarbital administration (390 mg /mL conc; administered 1 $\mathrm{mL} / 5 \mathrm{~kg} \mathrm{BW}$ ) and disposed of according to NIH-CDC biosafety level 2 procedures ${ }^{[9]}$ at the Kansas State University Veterinary Diagnostic Laboratory.

Table 1: Diet composition ${ }^{\mathrm{a}}$

\begin{tabular}{lr}
\hline Corn $^{\mathrm{b}}$ & 64.04 \\
Soybean meal, 46.5\% $\mathrm{CP}^{\mathrm{b}}$ & 32.89 \\
Monocalcium phosphate & 1.22 \\
Limestone & 1.10 \\
Salt & 0.35 \\
Vitamin premix $^{\mathrm{c}}$ & 0.25 \\
Trace mineral premix $^{\mathrm{d}}$ & 0.15 \\
\hline
\end{tabular}

${ }^{\mathrm{a}}$ Diet was formulated to contain $1.15 \%$ lysine,

$0.75 \% \mathrm{Ca}$ and $0.65 \% \mathrm{P}$.

${ }^{\mathrm{b}}$ Calculated values for lysine from NRC (1988) and NCR-42 (1992), for corn and soybean meal, respectively, were used in diet formulation.

${ }^{c}$ Provided the following per kilogram of complete diet: vitamin $\mathrm{A}, 11,023 \mathrm{IU}$; vitamin $\mathrm{D}_{3}, 1654 \mathrm{IU}$; vitamin $\mathrm{E}, 44$ IU; menadione (menadione sodium bisulfate complex), 4.4 $\mathrm{mg}$; riboflavin, $9.9 \mathrm{mg}$; pantothenic acid, $33 \mathrm{mg}$; niacin, 55 $\mathrm{mg}$; vitamin $\mathrm{B}_{12}, 44 \mathrm{mcg}$.

${ }^{\mathrm{d}}$ Provided the following per kilogram of complete diet: $\mathrm{Mn}$, 40 mg; Fe, 165 mg; Zn, 165 mg; Cu, 17 mg; I, 298 mcg; Se, $298 \mathrm{mcg}$.

Pair-feeding procedure. Each pair-fed control pig was matched to one S. typhimurium challenged pig on experimental $\mathrm{d}-4$ based upon initial body weight, and remained paired throughout the entire experiment. Pair feeding was accomplished by feeding the pair-fed control pig the previous $24 \mathrm{~h}$ net feed intake of its assigned $S$. typhimurium challenged pig. The pairfeeding was performed to control for responses that depend on feed intake.

Housing and $N$ balance. All pigs were housed in the same facility within two environmentally controlled rooms separated by a common hallway with constant lighting ${ }^{[7]}$. Pigs were housed based upon health status and were individually housed in adjustable stainless steel metabolism cages $(1.5 \mathrm{~m} \times 0.9 \mathrm{~m})$ that allowed separate collection of feces and urine. The marker to marker method $(0.5 \%$ ferric oxide in the first meal of each consecutive period, and the eighth subsequent meal occurring on $\mathrm{d} 11$ and d 17) was used to determine the beginning and end of feces collection for a period. Feces were collected twice daily and stored at $-10^{\circ} \mathrm{C}$. 
At the end of each period, feces were autoclaved at $132^{\circ} \mathrm{C}$ for $30 \mathrm{~min}$ to kill pathogens before being homogenized and sub-sampled. All feces were double bagged, and kept in a closed box to minimized gaseous losses during the autoclave procedure. Urine was collected daily in polypropylene bottles containing 75 $\mathrm{mL}$ of $6 \mathrm{~N} \mathrm{HCl}$. Ten percent of the daily urine volume was sub-sampled and stored at $-10^{\circ} \mathrm{C}$ until laboratory analysis. Urine was thawed, and then centrifuged at $2000 \times g$ to remove particulate matter before further sub-sampling prior to analysis. Feed samples were ground through a $1 \mathrm{~mm}$ screen before analysis. Feed, feces, and urine were analyzed for $\mathrm{N}$ on an as-is basis to minimize any loss of gaseous ammonia before analysis $^{[8]}$. Feed, feces, and urine were analyzed for N, $\mathrm{DM}$ and $\mathrm{GE}$ according to AOAC ${ }^{[10]}$ procedures. The values obtained were then used to calculate apparent digestibilities, DE and ME intakes, and $\mathrm{N}$ retention.

Insulin-like growth factor-I, and acute phase proteins assays. Plasma and serum samples were harvested from blood samples drawn via jugular venipuncture using heparinized and nonheparinized vacuum tubes on $\mathrm{d}-3,1,5,9$, and 15 at least $4 \mathrm{~h}$ after the 0630 feeding. The samples were analyzed for IGFI, serum haptogolobin, and AGP concentrations. Plasma IGF-I concentrations were determined using a commercially available two-site immunoradiometric assay (Diagnostic Systems Laboratories, Webster TX). This assay was validated for porcine IGF-I in our laboratory ${ }^{[7]}$, and has a detection limit of $0.4 \mathrm{ng} / \mathrm{mL}$, with inter- and intra-assay precision coefficients of variation of $4.47 \%$ and $2.63 \%$, respectively. Serum haptoglobin concentrations were determined colorimetrically using procedures described by Smith et $a l^{[11]}$. This assay has a designed sensitivity from 0 to $150 \mathrm{mg} \mathrm{Hgb/dL}$, with inter and intra-assay variabilities of $4.8 \%$ and $5.5 \%$, respectively. Serum AGP concentrations were determined using a commercially available radial immunodiffusion assay (Cardio-Tech Services, Louisville KY). The AGP assay has detection limits from 50 to $1,500 \mathrm{mcg} / \mathrm{mL}$, with an intra-assay variablity of less than $4 \%$. Although our assay is from a different supplier, it is the same assay previously utilized for porcine AGP determination ${ }^{[4,5,12]}$.

Statistics. All data were analyzed using a mixed model split-plot ANOVA for repeated measures with a Satterthwaite error correction $\left.{ }^{[13}, 14,15\right]$. The model included the treatment effect in the main plot (animal within treatment variance), and the effects of time period and the treatment $\times$ time period interaction in the subplot. Comparisons between treatments, within sampling times were made only when a significant $F$ - test for the treatment $\times$ time interaction or the treatment effect was found. Individual pig was the experimental unit. Subsequent periodic samples by pig were used for the repeated measures. Because only 6 or 8 pigs could be used at a time, pigs were blocked by allotment group and were randomly assigned to treatment within each block. Linear and quadratic polynomial contrasts were used to determine the effects of $S$. typhimurium challenge over time on all response criteria ${ }^{[16]}$.

Only pigs that completed all five $\mathrm{N}$ balance collection periods were used in the statistical analysis. Thus, 21 S. typhimurium challenged pigs, 8 pair-fed control pigs, and 6 ad libitum control pigs successfully completed the study, and were included in the statistical analysis. Two S. typhimurium challenge pigs died, of which one had a pair fed control. Both challenge pigs, and the pair-fed control pig were removed from the experiment and were excluded from the analyses.

\section{RESULTS}

Acute phase proteins and IGF-I. A treatment by time interaction was observed for haptoglobin concentration $(\mathrm{P}<0.05$; Table 2). Day 1 and 5 serum haptoglobin levels were higher for the $S$. typhimurium challenged pigs than for the ad libitum control pigs $(\mathrm{P}<$ 0.05). Haptoglobin levels of pair fed control pigs were intermediate to those of the other treatments and differed from those of the $S$. typhimurium challenged pigs on $\mathrm{d} 5$ and 9 ( $\mathrm{P}<0.05 ; \mathrm{P}<0.10$, respectively). Serum AGP levels were not different among treatments before the disease challenge. Serum AGP levels for the $S$. typhimurium challenged pigs differed from levels of the ad libitum controls on $\mathrm{d} 5$ and 9 postchallenge $(\mathrm{P}<$ 0.04). The pair fed controls were intermediate between the other two treatments, and tended to differ from the S. typhimurium challenged pigs on d 5 and $9(\mathrm{P}<0.14)$.

Concentrations of IGF-I increased regardless of treatment from $\mathrm{d}-3$ to 15 (linear, $\mathrm{P}<0.05$ ). Levels of IGF-I were highest in the $S$. typhimurium challenged pigs on $\mathrm{d} 9$, and differed from those of the pair fed controls on $\mathrm{d} 9$ and the ad libitum control pigs on $\mathrm{d} 15$ $(\mathrm{P}<0.05)$. A tendency for increased d 9 IGF-I levels was observed for the S. typhimurium challenged pigs vs the ad libitum control pigs $(\mathrm{P}<0.10)$. The increased levels of IGF-I were concurrent with the improvements in performance and $\mathrm{N}$ retention of the $S$. typhimurium challenged pigs during the recovery and post recovery periods, as compared with $\mathrm{d} 0$ to 3 performance. 
Table 2: Effects of S. typhimurium challenge and feeding regimen on selected acute phase proteins and insulinlike growth factor-I in 32 to $54 \mathrm{~kg} \mathrm{pigs}^{\mathrm{a}}$

\begin{tabular}{|c|c|c|c|c|c|c|c|}
\hline \multirow[b]{2}{*}{ Criteria } & \multirow{2}{*}{$\begin{array}{c}\text { Days } \\
\text { Post- } \\
\text { challenge }\end{array}$} & \multirow{2}{*}{ 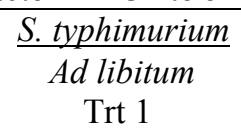 } & \multicolumn{2}{|c|}{ Nonchallenged } & \multicolumn{3}{|c|}{ Probability $(\mathrm{P}<)$} \\
\hline & & & $\begin{array}{l}\text { Ad libitum } \\
\text { Trt } 2\end{array}$ & $\begin{array}{c}\text { Pair-fed } \\
\text { Trt } 3\end{array}$ & 1 vs. 2 & 1 vs. 3 & 2 vs. 3 \\
\hline$n$ & & 21 & 6 & 8 & & & \\
\hline \multicolumn{8}{|c|}{ Haptoglobin, mg Hgb/dL ${ }^{b}$} \\
\hline & -3 & $39 \pm 6$ & $48 \pm 9$ & $42 \pm 8$ & 0.22 & 0.67 & 0.46 \\
\hline & 1 & $57 \pm 6$ & $39 \pm 9$ & $51 \pm 8$ & 0.02 & 0.39 & 0.18 \\
\hline & 5 & $69 \pm 6$ & $31 \pm 9$ & $47 \pm 8$ & 0.001 & 0.002 & 0.07 \\
\hline & 9 & $48 \pm 6$ & $38 \pm 9$ & $34 \pm 8$ & 0.22 & 0.06 & 0.66 \\
\hline & 15 & $39 \pm 7$ & $28 \pm 9$ & $39 \pm 8$ & 0.20 & 0.99 & 0.26 \\
\hline \multicolumn{8}{|c|}{ AGP, $\mu \mathrm{g} / \mathrm{mL}^{\mathrm{c}}$} \\
\hline & -3 & $725 \pm 61$ & $685 \pm 113$ & $843 \pm 98$ & 0.76 & 0.31 & 0.29 \\
\hline & 1 & $647 \pm 61$ & $680 \pm 113$ & $706 \pm 98$ & 0.80 & 0.61 & 0.86 \\
\hline & 5 & $871 \pm 61$ & $602 \pm 113$ & $693 \pm 98$ & 0.04 & 0.13 & 0.54 \\
\hline & 9 & $821 \pm 61$ & $553 \pm 113$ & $650 \pm 98$ & 0.04 & 0.14 & 0.52 \\
\hline & 15 & $648 \pm 62$ & $571 \pm 124$ & $600 \pm 98$ & 0.58 & 0.68 & 0.86 \\
\hline \multicolumn{8}{|c|}{ IGF-I, ng/mL ${ }^{\mathrm{d}}$} \\
\hline & -3 & $342 \pm 35$ & $289 \pm 50$ & $305 \pm 47$ & 0.28 & 0.42 & 0.78 \\
\hline & 1 & $293 \pm 35$ & $331 \pm 50$ & $323 \pm 45$ & 0.44 & 0.50 & 0.88 \\
\hline & 5 & $306 \pm 35$ & $333 \pm 50$ & $334 \pm 45$ & 0.58 & 0.53 & 0.99 \\
\hline & 9 & $433 \pm 35$ & $340 \pm 50$ & $326 \pm 47$ & 0.06 & 0.02 & 0.81 \\
\hline & 15 & $401 \pm 35$ & $293 \pm 50$ & $357 \pm 45$ & 0.03 & 0.32 & 0.25 \\
\hline
\end{tabular}

${ }^{a}$ Thirty five pigs were used in a randomized incomplete block design with individual pig as the experimental unit. typhimurium challenge occurred on $\mathrm{d} 0$.

${ }^{\mathrm{b}}$ Serum haptoglobin treatment $\times$ time interaction $(\mathrm{P}<0.05)$.

${ }^{c}$ Alpha-1 acid glycoprotein tendency for a treatment effect $(\mathrm{P}<0.11)$ and a linear time effect $(\mathrm{P}<0.09)$.

${ }^{\mathrm{d}}$ Plasma IGF-I linear time effect $(\mathrm{P}<0.05)$.

Growth performance. A treatment by time interaction $(\mathrm{P}<0.05)$ was observed for average daily gain (ADG; Table 3), resulting from decreased ADG (P $<0.01$ ) from d 0 to 3 for the $S$. typhimurium challenged pigs vs the ad libitum control pigs. The pair-fed control pigs tended to have intermediate ADG $(\mathrm{P}<0.07)$. Average daily feed intake (ADFI) tended to differ among treatments $(\mathrm{P}<0.06)$, primarily as a result of changes in d 0 to 3 ADFI between the $S$. typhimurium challenged pigs and the ad libitum control pigs. The $\mathrm{d}$ 0 to 17 ADFI was $1.85,1.89$, and $1.74 \mathrm{~kg}$, for the $S$. typhimurium challenged, ad libitum control, and the pair-fed control pigs, respectively. Unexpectedly, from d -4 to -1 , ADFI was less for the pair-fed controls than for the $S$. typhimurium challenged pigs $(\mathrm{P}<0.05)$ and tended to be higher for S. typhimurium challenged pigs than for the ad libitum controls $(\mathrm{P}<0.06)$. In addition, feed efficiency $(\mathrm{G} / \mathrm{F})$ appeared numerically worse for $S$. typhimurium challenged pigs compared to pair-fed controls from $\mathrm{d} 0$ to 3 , but no overall treatment difference was observed. Additionally, while initial pig weights were numerically lower $(\mathrm{P}>0.10)$ for the pairfed control pigs vs the ad libitum fed control pigs, no effect was observed for either initial or final pig weight. In general, differences in growth performance were observed only from d 0 to 3 after the challenge.

$N$ and DM Digestibility and Energy Balance. Treatment by time interactions were also observed for apparent DM $(\mathrm{P}<0.05)$ and $\mathrm{N}(\mathrm{P}<0.06)$ digestibility (Table 4). The apparent DM digestibility was greater for S. typhimurium challenged pigs compared to control ad libitum pigs $(\mathrm{P}<0.05)$ from $\mathrm{d} 8$ to 11 and $\mathrm{d} 14$ to 17 , and tended to be greater when compared to the pair fed controls from d 8 to $17(\mathrm{P}<0.10)$. Apparent $\mathrm{DM}$ digestibility from $\mathrm{d} 4$ to 7 also increased for the pair fed control pigs compared to the ad libitum control pigs (P $<0.03)$. The S. typhimurium challenged pigs had increased DM digestibility from d 0 to 17 vs the ad libitum control pigs $(\mathrm{P}<0.05)$. Additionally, DM digestibility tended to be better for the pair fed control pigs than for the ad libitum control pigs from d 0 to 17 $(\mathrm{P}<0.08)$. 
Table 3: Effects of S. typhimurium challenge and feeding regimen on growth performance in 32 to $54 \mathrm{~kg}$ pigs $^{\mathrm{a}}$

\begin{tabular}{|c|c|c|c|c|c|c|c|}
\hline \multirow[b]{2}{*}{ Criteria } & \multirow{2}{*}{$\begin{array}{c}\text { Days } \\
\text { Post- } \\
\text { challenge }\end{array}$} & \multirow{2}{*}{ 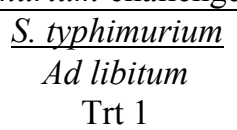 } & \multicolumn{2}{|c|}{ Nonchallenged } & \multicolumn{3}{|c|}{ Probability $(\mathrm{P}<)$} \\
\hline & & & $\begin{array}{c}\text { Ad libitum } \\
\text { Trt } 2 \\
\end{array}$ & $\begin{array}{c}\text { Pair-fed } \\
\text { Trt } 3\end{array}$ & 1 vs. 2 & 1 vs. 3 & 2 vs. 3 \\
\hline \multicolumn{8}{|l|}{$\overline{\mathrm{ADG}}, \mathrm{kg}^{\mathrm{b}}$} \\
\hline & -4 to -1 & $1.15 \pm 0.10$ & $1.02 \pm 0.18$ & $1.19 \pm 0.16$ & 0.52 & 0.85 & 0.48 \\
\hline & 0 to 3 & $0.62 \pm 0.10$ & $1.38 \pm 0.18$ & $0.95 \pm 0.16$ & 0.01 & 0.07 & 0.06 \\
\hline & 4 to 7 & $1.10 \pm 0.10$ & $0.88 \pm 0.18$ & $1.13 \pm 0.16$ & 0.26 & 0.88 & 0.28 \\
\hline & 8 to 11 & $1.01 \pm 0.10$ & $1.06 \pm 0.18$ & $1.10 \pm 0.16$ & 0.80 & 0.63 & 0.87 \\
\hline & 14 to 17 & $1.07 \pm 0.10$ & $1.13 \pm 0.18$ & $0.94 \pm 0.16$ & 0.77 & 0.47 & 0.41 \\
\hline & 0 to 17 & $0.96 \pm 0.07$ & $1.10 \pm 0.11$ & $1.01 \pm 0.10$ & 0.21 & 0.58 & 0.49 \\
\hline \multicolumn{8}{|l|}{ ADFI, $\mathrm{kg}^{\mathrm{c}}$} \\
\hline & -4 to -1 & $1.60 \pm 0.11$ & $1.37 \pm 0.14$ & $1.37 \pm 0.13$ & 0.06 & 0.04 & 0.96 \\
\hline & 0 to 3 & $1.34 \pm 0.11$ & $1.64 \pm 0.14$ & $1.39 \pm 0.13$ & 0.01 & 0.53 & 0.08 \\
\hline & 4 to 7 & $1.82 \pm 0.11$ & $1.89 \pm 0.14$ & $1.65 \pm 0.13$ & 0.53 & 0.14 & 0.09 \\
\hline & 8 to 11 & $1.95 \pm 0.11$ & $1.91 \pm 0.14$ & $1.86 \pm 0.13$ & 0.70 & 0.42 & 0.76 \\
\hline & 14 to 17 & $2.26 \pm 0.11$ & $2.28 \pm 0.14$ & $2.14 \pm 0.13$ & 0.92 & 0.25 & 0.32 \\
\hline & 0 to 17 & $1.85 \pm 0.11$ & $1.89 \pm 0.13$ & $1.74 \pm 0.12$ & 0.68 & 0.22 & 0.15 \\
\hline \multicolumn{8}{|l|}{$\mathrm{G} / \mathrm{F}^{\mathrm{d}}$} \\
\hline & -4 to -1 & $0.73 \pm 0.10$ & $0.81 \pm 0.18$ & $0.91 \pm 0.16$ & 0.70 & 0.31 & 0.65 \\
\hline & 0 to 3 & $0.20 \pm 0.10$ & $0.84 \pm 0.18$ & $0.62 \pm 0.16$ & 0.01 & 0.02 & 0.36 \\
\hline & 4 to 7 & $0.62 \pm 0.10$ & $0.48 \pm 0.18$ & $0.74 \pm 0.16$ & 0.49 & 0.51 & 0.27 \\
\hline & 8 to 11 & $0.53 \pm 0.10$ & $0.55 \pm 0.18$ & $0.59 \pm 0.16$ & 0.90 & 0.73 & 0.87 \\
\hline & 14 to 17 & $0.48 \pm 0.10$ & $0.50 \pm 0.18$ & $0.45 \pm 0.16$ & 0.91 & 0.89 & 0.84 \\
\hline & 0 to 17 & $0.49 \pm 0.06$ & $0.58 \pm 0.11$ & $0.59 \pm 0.09$ & 0.44 & 0.34 & 0.94 \\
\hline \multicolumn{8}{|l|}{ Pig wt, $\mathrm{kg}$} \\
\hline & -4 & $32.2 \pm 0.4$ & $33.0 \pm 0.7$ & $30.9 \pm 0.6$ & 0.39 & 0.11 & 0.03 \\
\hline & 17 & $54.0 \pm 0.8$ & $56.9 \pm 1.5$ & $54.0 \pm 1.3$ & 0.11 & 0.97 & 0.13 \\
\hline
\end{tabular}

${ }^{a}$ Thirty five pigs were used in a randomized incomplete block design with individual pig as the experimental unit. S. typhimurium challenge occurred on d 0 .

${ }^{\mathrm{b}} \mathrm{A}$ treatment $\times$ time interaction was observed for $\mathrm{ADG}(\mathrm{P}<0.05)$.

${ }^{\mathrm{c}} \mathrm{A}$ tendency for a treatment effect $(\mathrm{P}<0.06)$, and linear and quadratic time effects $(\mathrm{P}<0.05)$ were observed for ADFI.

${ }^{\mathrm{d}}$ Linear time effect $(\mathrm{P}<0.05)$ was observed for $\mathrm{G} / \mathrm{F}$.

Energy intake was evaluated during $\mathrm{d} 0$ to 3 and $\mathrm{d}$ 8 to 11 to determine how time and treatment changes associated with changes in apparent DM digestibility during these periods may have affected digestible and metabolizable energy. Gross energy intake, expressed as MJ per day intake, increased regardless of treatment from $\mathrm{d} 0$ to 3 to $\mathrm{d} 8$ to $11(\mathrm{P}<0.01)$. A tendency for a treatment $\times$ time interaction was observed for $\mathrm{DE}$, as a percent of GE intake. This interaction was a result of a tendency for increased $\mathrm{DE}$ of $S$. typhimurium challenged pigs vs the ad libitum fed controls $(\mathrm{P}<0.08)$ and the pair-fed controls $(\mathrm{P}<0.06)$ from $\mathrm{d} 8$ to 11 . No differences were observed for ME, as a percent of GE intake $(P>0.10)$, or for efficiency of ME utilization for gain $(\mathrm{P}>0.10)$.
$N$ Balance. Treatment by time interactions were observed for fecal $\mathrm{N}$ and retained $\mathrm{N}(\mathrm{P}<0.05$; Table 5). These interactions resulted from decreased $\mathrm{N}$ retention during the acute challenge period ( 0 to 3 ), indicating a reduction in lean growth rate for both pair-fed control and the S. typhimurium challenged pigs compared to the ad libitum control pigs. The fecal $\mathrm{N}$ interaction resulted from changes in fecal $\mathrm{N}$ content from $\mathrm{d} 8$ to 11 for the S. typhimurium challenged pigs vs both control treatments $(\mathrm{P}<0.04)$. Fecal N was also lower for the $S$. typhimurium and pair fed control pigs from d 0 to 17 when compared to the ad libitum control pigs $(\mathrm{P}<$ 0.05). Tendencies for differences in $\mathrm{N}$ intake, $\mathrm{N}$ retention, and fecal $\mathrm{N}(\mathrm{P}<0.10)$ between pair-fed and ad libitum controls were the result of decreases in ADFI 
Table 4: Effects of S. typhimurium challenge and feeding regimen on apparent dry matter and apparent nitrogen digestibility and apparent energy balance in 32 to $54 \mathrm{~kg} \mathrm{pigs}^{\mathrm{a}}$

\begin{tabular}{|c|c|c|c|c|c|c|c|}
\hline \multirow{2}{*}{ Criteria } & \multirow{2}{*}{$\begin{array}{c}\text { Days } \\
\text { Post- } \\
\text { challenge }\end{array}$} & \multirow{2}{*}{$\begin{array}{c}\frac{\text { S. typhimurium }}{\text { Ad libitum }} \\
\text { Trt } 1\end{array}$} & \multicolumn{2}{|c|}{ Nonchallenged } & \multicolumn{3}{|c|}{ Probability $(\mathrm{P}<)$} \\
\hline & & & $\begin{array}{l}\text { Ad libitum } \\
\text { Trt } 2\end{array}$ & $\begin{array}{l}\text { Pair-fed } \\
\text { Trt } 3\end{array}$ & 1 vs. 2 & 1 vs. 3 & 2 vs. 3 \\
\hline \multicolumn{8}{|c|}{ App. DM dig., $\%^{b}$} \\
\hline & -4 to -1 & $87.5 \pm 0.4$ & $87.2 \pm 0.8$ & $87.1 \pm 0.6$ & 0.72 & 0.55 & 0.89 \\
\hline & 0 to 3 & $86.3 \pm 0.4$ & $86.4 \pm 0.6$ & $86.3 \pm 0.6$ & 0.83 & 0.98 & 0.84 \\
\hline & 4 to 7 & $86.7 \pm 0.4$ & $86.0 \pm 0.6$ & $87.8 \pm 0.6$ & 0.27 & 0.10 & 0.03 \\
\hline & 8 to 11 & $87.6 \pm 0.4$ & $85.0 \pm 0.6$ & $85.9 \pm 0.6$ & 0.01 & 0.02 & 0.27 \\
\hline & 14 to 17 & $88.0 \pm 0.4$ & $86.5 \pm 0.6$ & $86.9 \pm 0.6$ & 0.04 & 0.10 & 0.63 \\
\hline & 0 to 17 & $87.1 \pm 0.2$ & $86.1 \pm 0.4$ & $86.8 \pm 0.3$ & 0.02 & 0.45 & 0.08 \\
\hline \multicolumn{8}{|c|}{ App. $\mathrm{N}$ dig., $\%^{\mathrm{c}}$} \\
\hline & -4 to -1 & $90.4 \pm 1.3$ & $89.4 \pm 2.7$ & $89.8 \pm 2.2$ & 0.74 & 0.81 & 0.92 \\
\hline & 0 to 3 & $83.8 \pm 1.2$ & $88.1 \pm 2.2$ & $89.2 \pm 1.9$ & 0.09 & 0.02 & 0.68 \\
\hline & 4 to 7 & $89.5 \pm 1.2$ & $88.2 \pm 2.2$ & $90.0 \pm 1.9$ & 0.58 & 0.85 & 0.53 \\
\hline & 8 to 11 & $89.5 \pm 1.2$ & $84.2 \pm 2.2$ & $85.9 \pm 1.9$ & 0.04 & 0.11 & 0.56 \\
\hline & 14 to 17 & $89.7 \pm 1.2$ & $85.7 \pm 2.2$ & $86.7 \pm 1.9$ & 0.11 & 0.28 & 0.75 \\
\hline & 0 to 17 & $88.1 \pm 0.7$ & $86.6 \pm 1.3$ & $88.0 \pm 1.1$ & 0.28 & 0.93 & 0.38 \\
\hline \multicolumn{8}{|c|}{ Energy Intake } \\
\hline \multicolumn{8}{|l|}{$\mathrm{GE}, \mathrm{MJ} / \mathrm{d}^{\mathrm{d}}$} \\
\hline & 0 to 3 & $19.9 \pm 1.7$ & $23.5 \pm 2.2$ & $20.0 \pm 2.1$ & 0.08 & 0.93 & 0.12 \\
\hline & 8 to 11 & $29.1 \pm 1.7$ & $27.5 \pm 2.2$ & $26.9 \pm 2.1$ & 0.43 & 0.24 & 0.80 \\
\hline \multicolumn{8}{|c|}{$\mathrm{DE}, \%$ of $G E^{\mathrm{e}}$} \\
\hline & 0 to 3 & $84.0 \pm 0.7$ & $84.7 \pm 1.1$ & $84.8 \pm 1.0$ & 0.56 & 0.42 & 0.91 \\
\hline & 8 to 11 & $86.1 \pm 0.7$ & $83.6 \pm 1.3$ & $83.8 \pm 1.1$ & 0.08 & 0.06 & 0.93 \\
\hline \multicolumn{8}{|c|}{$\mathrm{ME}, \%$ of GE } \\
\hline & 0 to 3 & $82.0 \pm 0.8$ & $82.8 \pm 1.3$ & $83.0 \pm 1.1$ & 0.59 & 0.44 & 0.89 \\
\hline & 8 to 11 & $84.3 \pm 0.8$ & $81.8 \pm 1.6$ & $81.9 \pm 1.3$ & 0.15 & 0.10 & 0.98 \\
\hline \multicolumn{8}{|c|}{ Efficiency, kg gain/MJ ME } \\
\hline & 0 to 3 & $0.01 \pm 0.02$ & $0.07 \pm 0.03$ & $0.05 \pm 0.02$ & 0.08 & 0.19 & 0.62 \\
\hline & 8 to 11 & $0.04 \pm 0.02$ & $0.05 \pm 0.03$ & $0.05 \pm 0.03$ & 0.90 & 0.78 & 0.93 \\
\hline
\end{tabular}

${ }^{a}$ Thirty five pigs were used in a randomized incomplete block design with individual pig as the experimental unit. S. typhimurium challenge occurred on $\mathrm{d} 0$.

${ }^{\mathrm{b}}$ Apparent DM digestibility treatment $\times$ time interaction $(\mathrm{P}<0.05)$.

${ }^{\mathrm{c}}$ Apparent $\mathrm{N}$ digestibility treatment $\times$ time interaction $(\mathrm{P}<0.06)$.

${ }^{\mathrm{d}}$ Time effects were observed for GE intake $(\mathrm{P}<0.01)$.

${ }^{\mathrm{e}}$ Digestible energy, as a percent of GE, treatment $\times$ time interaction $(\mathrm{P}<0.06)$.

of the pair fed pigs from $\mathrm{d} 0$ to 3 . Nitrogen intake was similar across treatments (quadratic, $\mathrm{P}<0.05$ ), except for the reduction associated with $\mathrm{d} 0$ to 3 ADFI for the $S$. typhimurium challenged $(\mathrm{P}<0.01)$ and pair fed control pigs $(\mathrm{P}<0.08)$ vs the ad libitum controls.
Similarly, urine $\mathrm{N}$ increased over time as a result of increased $\mathrm{N}$ intake (quadratic, $\mathrm{P}<0.05$ ).

$N$ Retention Efficiency. A linear time effect was observed for the percentage of $\mathrm{N}$ intake retained $(\mathrm{P}<$ 0.05 ), indicating that $\mathrm{N}$ retention efficiency, relative to 
$\mathrm{N}$ intake, decreased over time (Table 5). Although no treatment effect was observed, d 0 to $3 \mathrm{~N}$ retention efficiency, both as percentage of $\mathrm{N}$ intake and of absorbed N, appeared numerically worse for $S$. typhimurium challenged pigs than for control ad libitum and pair fed control pigs.

\section{DISCUSSION}

Acute phase proteins. The rise in serum haptoglobin concentrations on $\mathrm{d} 1$ and 5 postchallenge for the $S$. typhimurium challenged pigs compared to either the ad libitum or pair-fed controls is typical of a nonspecific, acute phase immune response $\mathrm{e}^{[12,17,18]}$. Increased serum haptoglobin concentrations are associated with increased immune function as interleukin-6 stimulates increased hepatic acute phase protein synthesis $^{[12]}$. Dritz et al ${ }^{[19]}$ also observed a twoto threefold increase in serum haptoglobin levels in pigs challenged with a noninfectious endotoxin compared to nonchallenged counterparts.

Increased serum AGP levels exhibited different kinetics than did serum haptoglobin but were still increased for the $S$. typhimurium challenged pigs on d 5 and 9 postchallenge. Serum haptoglobin levels increased more rapidly than AGP levels, with $S$. typhimurium challenged pigs showing increased concentrations by d 1 postchallenge. Although Webel et al [5] did not observe increased serum AGP concentrations following an endotoxin challenge in growing pigs, others have observed increased serum AGP concentrations in pigs singularly ${ }^{[20]}$ or continuously $^{[4]}$ reintroduced to immune stimulation compared to segregated early-weaned counterparts. The difference in results between Webel et al ${ }^{[5]}$ and the results herein may be due to the short time course of their measurements. They observed the immune response to a single endotoxin challenge for $24 \mathrm{~h}$ postchallenge, which may have been too short of a period to observe an AGP response. Our results indicate that serum AGP concentrations for the $S$. typhimurium challenged pigs did not increase above basal levels until somewhere between 1 and $5 \mathrm{~d}$ postchallenge. Finally, the lack of an acute phase response by the control nonchallenged pigs in our study indicates that our biosecurity procedures were adequate to prevent unintentional infection of those pigs.

Insulin-like growth factor-I. Research by Wright et $a l^{[21]}$, Balaji et $a l^{[7]}$, and Burkey et al ${ }^{[22]}$ indicated that plasma IGF-I concentrations in 15 kilogram pigs temporarily decline with an acute $S$. typhimurium disease challenge or a noninfectious endotoxin challenge, respectively. Balaji et al ${ }^{[7]}$ indicated that IGF-I levels recover to control levels within $120 \mathrm{~h}$ after the infectious challenge. The lack of significant decreases in IGF-I concentrations after challenge, and the lack of long term reductions in growth performance and $\mathrm{N}$ balance indicate that the $S$. typhimurium challenged pigs had a more moderate, shorter duration systemic immune response, compared to the response

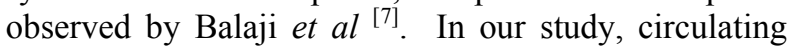
IGF-I concentrations appear to be positively correlated with increased growth rate following the acute immune challenge. Because the $S$. typhimurium challenge dose and administration methodology for our study, and that of Balaji et al ${ }^{[7]}$ were essentially identical, the larger pigs used in our experiment may have contribute to the lack of significant reductions in plasma IGF-I. Furthermore, in another study by Johnson et al ${ }^{[24]}$, despite the unmistakable decrease in stystmic IGF-I the relative the relative abundance of skeletal muscle IGF-I mRNA was unaffected. This indicates that short term dynamics of IGF-I systemic concentration may have minimal effects on muscle growth and provide further agreement with our data. In a study evaluating Actinobacillus pleuropneumonia challenge, Loughmiller et al ${ }^{[23]}$ observed a slight decline in initial IFG-I concentrations; however, they increased by day 9 post challenge. While the plasma IGF-I concentrations were not significantly lower in the study herein, they were numerically lowest for the $S$. typhimurium challenged pigs on $\mathrm{d} 1$ and 5 compared to both control treatments.

The effect of an acute disease challenge upon plasma IGF-I concentrations is mediated in part by decreased feed intake ${ }^{[24]}$. Feed intake, growth hormone, insulin, and thyroid hormones $\mathrm{T}_{3}$ and $\mathrm{T}_{4}$ are all established factors in the regulation of plasma IGF-I concentrations ${ }^{[25]}$. Buonomo and Baile ${ }^{[26]}$ observed that plasma IGF-I levels decreased in pigs from whom feed was withheld for $48 \mathrm{~h}$, and that during feed restriction, plasma IGF-I concentrations did not respond to increased levels of plasma growth hormone. Although plasma IGF-I concentrations reported herein were not affected through $\mathrm{d} 5$ by immune status or feeding regimen, increasing levels of plasma IGF-I on d 9 and 15 postchallenge further corroborated the compensatory digestibility effect observed for apparent $\mathrm{DM}$ and $\mathrm{N}$ digestibilities from $\mathrm{d} 8$ to 17 postchallenge. Our results also indicate that long-term effects of an acute $S$. typhimurium infection are minimal under highly controlled conditions.

Growth performance. Our results indicate that the effects of an acute $S$. typhimurium infection on growth 
American J. Animal \& Vety. Sci., 2 (1): 11-22, 2007

Table 5: Effects of S. typhimurium challenge and feeding regimen on nitrogen balance and $\mathrm{N}$ retention efficiency in 32

\begin{tabular}{|c|c|c|c|c|c|c|c|}
\hline \multirow[b]{2}{*}{ Criteria } & Days & \multirow{2}{*}{$\begin{array}{c}\frac{\text { S. typhimurium }}{\text { Ad libitum }} \\
\text { Trt } 1\end{array}$} & \multicolumn{2}{|c|}{ Nonchallenged } & \multicolumn{3}{|c|}{ Probability $(\mathrm{P}<)$} \\
\hline & $\begin{array}{c}\text { Post- } \\
\text { challenge }\end{array}$ & & $\begin{array}{l}\text { Ad libitum } \\
\text { Trt } 2\end{array}$ & $\begin{array}{l}\text { Pair-fed } \\
\text { Trt } 3\end{array}$ & 1 vs. 2 & 1 vs. 3 & 2 vs. 3 \\
\hline \multicolumn{8}{|c|}{$\mathrm{N}$ intake, $\mathrm{g} / \mathrm{d}^{\mathrm{b}}$} \\
\hline & -4 to -1 & $50.7 \pm 3.6$ & $43.6 \pm 4.6$ & $44.6 \pm 4.3$ & 0.07 & 0.08 & 0.83 \\
\hline & 0 to 3 & $42.4 \pm 3.6$ & $52.3 \pm 4.6$ & $44.5 \pm 4.3$ & 0.01 & 0.54 & 0.08 \\
\hline & 4 to 7 & $58.0 \pm 3.6$ & $60.5 \pm 4.6$ & $52.9 \pm 4.3$ & 0.51 & 0.15 & 0.09 \\
\hline & 8 to 11 & $62.3 \pm 3.6$ & $60.9 \pm 4.6$ & $59.6 \pm 4.3$ & 0.72 & 0.44 & 0.76 \\
\hline & 14 to 17 & $72.1 \pm 3.6$ & $72.8 \pm 4.6$ & $68.3 \pm 4.3$ & 0.87 & 0.28 & 0.31 \\
\hline & 0 to 17 & $56.9 \pm 3.3$ & $58.0 \pm 3.9$ & $54.0 \pm 3.7$ & 0.70 & 0.29 & 0.20 \\
\hline \multicolumn{8}{|c|}{ Fecal N, g/d } \\
\hline & -4 to -1 & $5.4 \pm 0.7$ & $5.3 \pm 1.1$ & $5.0 \pm 0.9$ & 0.86 & 0.64 & 0.85 \\
\hline & 0 to 3 & $5.9 \pm 0.7$ & $5.8 \pm 0.9$ & $4.5 \pm 0.9$ & 0.90 & 0.07 & 0.19 \\
\hline & 4 to 7 & $6.3 \pm 0.7$ & $6.8 \pm 0.9$ & $5.2 \pm 0.9$ & 0.51 & 0.15 & 0.09 \\
\hline & 8 to 11 & $6.7 \pm 0.7$ & $9.2 \pm 0.9$ & $8.3 \pm 0.9$ & 0.005 & 0.04 & 0.35 \\
\hline & 14 to 17 & $7.7 \pm 0.7$ & $9.9 \pm 0.9$ & $8.8 \pm 0.9$ & 0.008 & 0.13 & 0.25 \\
\hline & 0 to 17 & $6.4 \pm 0.7$ & $7.5 \pm 0.8$ & $6.4 \pm 0.7$ & 0.03 & 0.97 & 0.05 \\
\hline \multicolumn{8}{|c|}{ Urinary $\mathrm{N}, \mathrm{g} / \mathrm{d}^{\mathrm{d}}$} \\
\hline & -4 to -1 & $15.9 \pm 2.3$ & $13.6 \pm 2.9$ & $14.1 \pm 2.7$ & 0.36 & 0.41 & 0.87 \\
\hline & 0 to 3 & $17.0 \pm 2.3$ & $16.2 \pm 2.9$ & $16.7 \pm 2.7$ & 0.71 & 0.86 & 0.85 \\
\hline & 4 to 7 & $18.9 \pm 2.3$ & $18.9 \pm 2.9$ & $16.4 \pm 2.7$ & 0.98 & 0.26 & 0.36 \\
\hline & 8 to 11 & $22.0 \pm 2.3$ & $23.1 \pm 2.9$ & $22.1 \pm 2.7$ & 0.65 & 0.94 & 0.73 \\
\hline & 14 to 17 & $28.8 \pm 2.3$ & $32.1 \pm 2.9$ & $28.7 \pm 2.7$ & 0.18 & 0.97 & 0.22 \\
\hline & 0 to 17 & $20.4 \pm 2.1$ & $20.8 \pm 2.4$ & $19.6 \pm 2.3$ & 0.82 & 0.61 & 0.51 \\
\hline \multicolumn{8}{|c|}{ Retained $\mathrm{N}, \mathrm{g} / \mathrm{d}^{\mathrm{e}}$} \\
\hline & -4 to -1 & $30.7 \pm 1.9$ & $25.4 \pm 3.7$ & $25.5 \pm 2.7$ & 0.18 & 0.13 & 0.98 \\
\hline & 0 to 3 & $19.6 \pm 1.9$ & $30.1 \pm 3.1$ & $23.2 \pm 2.7$ & 0.002 & 0.23 & 0.07 \\
\hline & 4 to 7 & $33.0 \pm 1.9$ & $34.5 \pm 3.1$ & $31.1 \pm 2.7$ & 0.65 & 0.54 & 0.38 \\
\hline & 8 to 11 & $33.7 \pm 1.9$ & $28.4 \pm 3.1$ & $29.1 \pm 2.7$ & 0.11 & 0.12 & 0.87 \\
\hline & 14 to 17 & $35.8 \pm 1.9$ & $30.5 \pm 3.1$ & $30.6 \pm 2.7$ & 0.12 & 0.09 & 0.98 \\
\hline & 0 to 17 & $30.5 \pm 1.3$ & $30.1 \pm 1.9$ & $28.1 \pm 1.7$ & 0.83 & 0.16 & 0.34 \\
\hline \multicolumn{8}{|c|}{$\mathrm{N}$ retention efficency } \\
\hline \multicolumn{8}{|c|}{$\%$ of $\mathrm{N}$ intake ${ }^{\mathrm{f}}$} \\
\hline & -4 to -1 & $59.5 \pm 4.0$ & $55.0 \pm 8.1$ & $55.0 \pm 6.7$ & 0.61 & 0.55 & 0.61 \\
\hline & 0 to 3 & $38.6 \pm 3.9$ & $57.0 \pm 6.7$ & $51.7 \pm 5.9$ & 0.02 & 0.05 & 0.02 \\
\hline & 4 to 7 & $57.8 \pm 3.9$ & $57.3 \pm 6.7$ & $59.4 \pm 5.9$ & 0.94 & 0.81 & 0.94 \\
\hline & 8 to 11 & $55.1 \pm 3.9$ & $46.6 \pm 6.7$ & $49.2 \pm 5.9$ & 0.26 & 0.38 & 0.26 \\
\hline & 14 to 17 & $51.0 \pm 3.9$ & $41.1 \pm 6.7$ & $44.9 \pm 5.9$ & 0.19 & 0.37 & 0.19 \\
\hline & 0 to 17 & $52.2 \pm 2.5$ & $51.2 \pm 3.7$ & $52.0 \pm 3.3$ & 0.80 & 0.95 & 0.86 \\
\hline \multicolumn{8}{|c|}{$\%$ of absorbed $\mathrm{N}$} \\
\hline & -4 to -1 & $65.5 \pm 7.2$ & $64.2 \pm 1.6$ & $63.2 \pm 1.3$ & 0.94 & 0.88 & 0.94 \\
\hline & 0 to 3 & $34.4 \pm 6.9$ & $65.5 \pm 1.3$ & $58.7 \pm 1.1$ & 0.04 & 0.07 & 0.04 \\
\hline & 4 to 7 & $63.9 \pm 6.9$ & $65.6 \pm 1.3$ & $66.7 \pm 1.1$ & 0.91 & 0.83 & 0.91 \\
\hline & 8 to 11 & $61.0 \pm 6.9$ & $56.2 \pm 1.3$ & $57.9 \pm 1.1$ & 0.75 & 0.81 & 0.75 \\
\hline & 14 to 17 & $56.4 \pm 6.9$ & $48.8 \pm 1.3$ & $52.3 \pm 1.1$ & 0.61 & 0.76 & 0.61 \\
\hline & 0 to 17 & $56.1 \pm 3.3$ & $59.7 \pm 6.1$ & $59.5 \pm 5.3$ & 0.60 & 0.58 & 0.98 \\
\hline
\end{tabular}

${ }^{a}$ Thirty five pigs were used in a randomized incomplete block design with individual pig as the experimental unit. $S$. typhimurium challenge occurred on $\mathrm{d} 0$.

${ }^{\mathrm{b}} \mathrm{N}$ intake linear and quadratic time effect $(\mathrm{P}<0.05)$.

${ }^{\mathrm{c}}$ Fecal $\mathrm{N}$ treatment $\times$ time interaction $(\mathrm{P}<0.05)$.

${ }^{\mathrm{d}}$ Urinary $\mathrm{N}$ linear and quadratic time effect $(\mathrm{P}<0.05)$.

${ }^{\mathrm{e}}$ Retained $\mathrm{N}$ treatment $\times$ time interaction $(\mathrm{P}<0.05)$.

${ }^{\mathrm{f}} \mathrm{N}$ retention efficiency, \% of $\mathrm{N}$ intake, linear time effect $(\mathrm{P}<0.05)$. 
performance are relatively short term for pigs of this age and weight. These observations are similar to those of Loughmiller et $a l^{[23]}$ who evaluated a single Actinobacillus pleuropneumonia challenge on pig growth and $\mathrm{N}$ metabolism. The decreased growth performance of the $S$. typhimurium challenged pigs occurred only during the challenge period (d 0 to 3 ). Prior to the challenge, the pigs in this treatment had similar gain and efficiency, and higher feed intake compared to pigs assigned to the two control treatments. While differences were apparent in $\mathrm{d}-4$ to -1 ADFI for the S. typhimurium challenged pigs and the pair fed control pigs, there was no difference in ADFI between the S. typhimurium pigs that were paired, and their unchallenged pair-fed counterparts (1.44 and 1.37 $\mathrm{kg}$, respectively; $\mathrm{P}>0.64)$. Furthermore, after the disease challenge, the pair fed control pigs had similar feed intakes as the S. typhimurium challenged pigs. This similarity indicates that the pair-feeding successfully controlled for effects dependent on changes in feed intake during and after the challenge period. Finally, d 0 to 17 ADFI indicates that overall post challenge feed intake was not influenced by disease challenge, thus the only differences are associated with the $\mathrm{d} 0$ to 3 challenge time period.

During the $\mathrm{d} 0$ to 3 challenge period, growth performance differences directly related to reduced feed intake accounted for $66 \%$ of the decreased ADG. An enteric disease challenge by $S$. typhimurium presumably causes increased concentrations of proinflammatory cytokines, which reduce feed intake ${ }^{[19,24,27]}$. This result is similar to observations of Dritz et al ${ }^{[19]}$ and van Heugten et al [28, 29], who used a noninfectious endotoxin challenge to stimulate an immune response. Although van Heugten et al ${ }^{[28,29]}$ observed short-term decreases in growth performance, they did not differentiate effects of feed intake reductions from effects specific to the immune response. Similar to our results, Dritz et al ${ }^{[19]}$ and Loughmiller et al ${ }^{[23]}$ who observed that the majority of the decreased performance during the acute phase immune response could be associated with reductions in feed intake. Although we concluded that most differences were feed intake related, additional short-term effects likely attributable to changes in metabolic processes were apparent. The lack of response in $\mathrm{G} / \mathrm{F}$ further indicates that the majority of the effects from the disease challenge are feed intake related. The lack of a G/F response indicates that the efficiency of feed utilization for gain was not altered by the acute phase response to the disease challenge. Thus, maintenance requirements of the challenged animals likely did not differ from the nonchallenged controls after the challenge occurred ${ }^{[23}$, ${ }^{28,29]}$. In contrast, Dritz et al ${ }^{[19]}$ and Williams et al ${ }^{[23]}$ observed decreased $\mathrm{G} / \mathrm{F}$ in immune stimulated pigs compared to nonchallenged counterparts. Dritz et al ${ }^{[19]}$ further observed decreased $\mathrm{G} / \mathrm{F}$ in the endotoxin challenged pigs in excess of that observed in their pairfed nonchallenged counterparts. However, both of these experiments utilized multiple immune stimulation challenge models, while our experiment utilized a single acute challenge. Thus, it appears that $\mathrm{G} / \mathrm{F}$ is not significantly affected by an acute $S$. typhimurium challenge.

The rapid recovery after challenge and similar performance of the S. typhimurium challenged pigs in comparison to both nonchallenged control treatments suggest that the immune activation associated with the disease challenge subsided rapidly after the challenge had been overcome. The similar performance after recovery indicates that the immune system in an inactive state, even after stimulation, does not impose a large burden upon the pig's metabolic processes. These results also indicate that when an environmental stressor is removed, performance will improve up to the limits imposed by the current environment ${ }^{[27,30]}$.

Digestibility. Similar to growth performance, apparent $\mathrm{DM}$ and $\mathrm{N}$ digestibilities were not affected by treatment prior to the disease challenge. In fact, apparent DM digestibility was not affected by treatment until the first recovery period, $\mathrm{d} 4$ to 7 after challenge, in which the pair-fed pigs had the highest DM digestibility of the three treatments. The lack of apparent DM digestibility differences from $\mathrm{d} 0$ to 3 and d 4 to 7 postchallenge between the $S$. typhimurium challenged pigs and the ad libitum control pigs indicates that inflammation and enterocyte death likely decreased the nutrient absorption efficiency of the $S$. typhimurium challenged pigs $^{[6]}$. This lowered absorption efficiency resulted in similar apparent DM digestibilities for $S$. typhimurium challenged pigs compared to the ad libitum controls, even though feed intake was lower for the $S$. typhimurium challenged pigs vs the ad libitum control pigs from d 0 to 3 postchallenge. If no intestinal damage occurred, then the apparent DM digestibility of the S. typhimurium challenged pigs should be similar to that of the pair fed controls, not the ad libitum controls. The reduced feed intakes associated with the $S$. typhimurium challenged pigs and the pair fed control pigs likely slowed ingesta passage rates. Thus, the increase in the apparent DM digestibility of the pair fed pigs is likely a result of more efficient nutrient absorption during the periods when feed intake was restricted ${ }^{[31]}$. 
Decreased apparent $\mathrm{N}$ digestibility previously has been implicated during an immune challenge ${ }^{[4,23]}$. That research suggested that it might be due to an increased intestinal wall thickness associated with the inflammation of the small intestine during a disease challenge. To support this, several studies have indicated a $S$. typhimurium challenge to produce elevation of proinflamatory cytokines localized in the tissues of the gut, whereas a LPS challenge produces a more systemic cytokine respons $\mathrm{e}^{[24]}$. Decreased apparent $\mathrm{N}$ digestibility during a $S$. typhimurium infection also would be consistent with research indicating that absorptive surface area of the small intestine is decreased by crypt cell and enterocyte necrotic lesions and sloughing of microvilli ${ }^{[6]}$. The temporary increase in apparent N digestibility of the $S$. typhimurium challenged pigs compared to the ad libitum controls from $\mathrm{d} 8$ to 11 further indicates that a compensatory apparent digestibility effect was involved in the recovery of these pigs from an acute $S$. typhimurium infection. This transient effect may have been associated with a reduction of bowel inflammation and the associated recovery of the intestinal microvilli.

Energy balance. Average DE and ME intakes of pigs in all three treatments from $\mathrm{d} 0$ to 3 and $\mathrm{d} 8$ to 11 postchallenge are in general agreement with estimated $\mathrm{DE}$ and ME intakes of pigs ranging from 10 to $50 \mathrm{~kg}$ [31]. This agreement suggests that energy intake was not limiting the performance of the ad libitum control pigs. Digestible energy, as a percent of GE intake, tended to increase for the S. typhimurium challenged pigs from $\mathrm{d} 8$ to 11 . This response is consistent with the increased apparent DM digestibility observed during the same period. It further suggests that digestibility was impaired during $\mathrm{d} 0$ to 3 postchallenge, and subsequently recovered once the probable gut inflammation associated with the enteric challenge subsided.

Similar to the results observed by van Huegten et $a l^{[28]}$ and Williams et al ${ }^{[29]}$ we did not observe any differences in the efficiency of ME utilization for gain. The lack of differences in energy utilization indicates that decreased energy intake lowers growth rates during an immune challenge, not alterations in ME utilization for gain. Therefore, consistent with previous research, our data indicates that the inflammatory response to an acute disease challenge affected protein metabolism, but did not affect the efficiency of energy utilization for gain.

$N$ Balance. Similar to growth performance and apparent digestibility, the lack of differences in $\mathrm{N}$ balance between treatments prior to the disease challenge indicates that all pigs were in a similar metabolic state from $\mathrm{d}-4$ to -1 . Observed differences in N intakes were results of decreased ADFI for the $S$. typhimurium challenged pigs and their pair fed counterparts from d 0 to 3 after challenge. Differences in fecal $\mathrm{N}$ concentrations were associated with differences observed in apparent DM and $\mathrm{N}$ digestibility, again suggesting a more efficient absorption of $\mathrm{N}$ intake after recovery from the disease challenge. In fact, fecal $\mathrm{N}$ was lower for $S$. typhimurium challenged pigs compared to ad libitum control pigs from d 8 to 17 , insomuch that differences in fecal $\mathrm{N}$ content were observed for the entire $\mathrm{d} 0$ to 17 postchallenge period. Although differences in fecal $\mathrm{N}$ can be explained by increased apparent $\mathrm{N}$ digestibility, differences in urinary $\mathrm{N}$ content did not exist. The lack of differences in urinary $\mathrm{N}$ content between all three treatments further indicates that the vast majority of the changes in N balance from an acute $S$. typhimurium challenge are associated with reductions in feed intake. Similar to other response criteria, retained $\mathrm{N}$ was only affected during the challenge period ( $\mathrm{d} 0$ to 3 ). The decrease in $\mathrm{N}$ retention was associated with decreased feed intake and decreased apparent $\mathrm{N}$ digestibility during this period. In addition, the lowest $\mathrm{N}$ retention was associated with pigs challenged with $S$. typhimurium, which further indicates that additional differences unique to the disease challenge decreased $\mathrm{N}$ balance beyond that associated with feed intake reductions in otherwise healthy pigs. This result is consistent with previous research by Williams et al ${ }^{[4]}$ who indicated that $\mathrm{N}$ retention is lower in pigs with chronic immune stimulation. Although Williams et al ${ }^{[4]}$ used a different disease challenge model, similarities exist between their results and our experiment during the acute phase response from d 0 to 3 after challenge. Both our results and the results of Williams et $a l^{[4]}$ and Loughmiller et al ${ }^{[23]}$ indicate an immune response to disease challenge reduces $\mathrm{N}$ balance during the immune response. Our results further indicate that once the immune challenge was overcome, immune system activity quickly subsided, and did not contribute to overall reductions in $\mathrm{N}$ balance from $\mathrm{d} 0$ to 17 after challenge. This response is in contrast to responses observed with a chronic immune challenge ${ }^{[4]}$. They observed that pigs with a high continual disease challenge from multiple pathogens had lower $\mathrm{N}$ balance and lysine utilization efficiencies overall. The difference in duration between their results and ours indicates that once the pig has overcome the disease challenge, immunological stimulation subsides. Because the immune system activity subsides, it does 
not reduce long term $\mathrm{N}$ balance. Conversely, we suggest that pathogens that are not quickly eliminated continue to stimulate the immune system and cause longer-term reductions.

$N$ retention efficiency. Similar to the $\mathrm{N}$ balance response, $\mathrm{N}$ retention efficiency, either as a portion of ADFI or of absorbed N, was only affected during the acute phase response from $\mathrm{d} 0$ to 3 . These results are similar to results of van Heugten $e t a l^{[29]}$, who observed decreased protein utilization efficiency in growing pigs challenged with a noninfectious endotoxin compared to nonchallenged controls injected with a sterile saline solution. We observed the greatest reductions in efficiency for S. typhimurium challenged pigs from d 0 to 3 postchallenge compared to either of the control treatments. Although a similar reduction in efficiency was observed for the pair fed controls compared to the ad libitum controls, feed intake explained only a portion of the efficiency reduction associated with the $S$. typhimurium challenged pigs. The additional reduction associated with the enteric disease challenge provides further evidence for the action of proinflammatory cytokines during the acute phase response of this experiment. As described above, the immune response to the disease challenge altered metabolism, decreased feed intake, and increased skeletal muscle catabolism; resulting in decreased $\mathrm{N}$ retention efficiency. Williams et $a l^{[4]}$ also reported decreased $\mathrm{N}$ retention efficiency due to an increased immune activation.

Finally, pigs raised under commercial conditions have shown longer-term reductions in total and lean growth rates ${ }^{[32]}$. This decrease in overall performance likely is due to the interplay of other factors outside of the acute disease challenge ${ }^{[30]}$. In contrast to commercial conditions, the pigs used in this experiment were maintained in a near ideal environment with minimal outside stress and received a similar infectious dose. The lack of additional stressors such as social interaction with penmates, reinfection from other pigs, and competition for feed and water likely contributed to their rapid recovery.

\section{IMPLICATIONS}

The results of this experiment indicate that reductions in performance associated with an acute $S$. typhimurium infection are due to both feed intake reductions and the acute phase immune response. The recovery processes after the disease challenge minimize any long-term effects. Field conditions typically have multiple stressors potentially leading to longer-term effects associated with an acute $S$. typhimurium infection. However, in a near optimal environment, metabolic alterations associated with an acute $S$. typhimurium infection in growing pigs appear to be primarily short-term.

\section{ACKNOWLEDGMENTS}

Appreciation is expressed to Robert Musser, Patrick O'Quinn, Scott Rustrum, Sue Chavey, Theresa Rathbun, Doreen Hyatt, Dr. J.E. Minton, Dallas Johnson, Karli Wright, Balaji Ramanathan, and Rusty Stott for their assistance in completing this experiment. Contribution No. 06-46-J of the Kansas Agric. Exp. Stat., Manhattan 66506.

\section{REFERENCES}

1. Dritz, S.S., J.L. Nelssen, R.D. Goodband, M.D. Tokach, and M.M. Chengappa, 1994. Application of segregated early weaning technology in the commercial swine industry. Comp. Cont. Educ. Pract. Vet. 16:677-685.

2. NAHMS, 1997. National Animal Health Monitoring System, Part III: Changes in the U.S. pork industry. USDA Animal and Plant Health Inspection Service Centers for Epidemiology and Animal Health. Fort Collins, CO.

3. Dritz, S.S., M.D. Tokach, R.D. Goodband, and J.L. Nelssen, 2002. An Evaluation of in-feed antimicrobial regimens in multi-site pig production systems. J. Am. Vet. Med. Assoc. 220:1690-1695.

4. Williams, N.H., T.S. Stahly, and D.R. Zimmerman, 1997a. Effect of chronic immune system activation on body $\mathrm{N}$ retention, partial efficiency of lysine utilization, and lysine needs of pigs. J. Anim. Sci. 75:2472-2480.

5. Webel, D.M., B.N. Finck, D.H. Baker, and R.W. Johnson, 1997. Time course of increased plasma cytokines, cortisol, and urea $\mathrm{N}$ in pigs following intraperitoneal injection of lipopolysaccharide. J. Anim. Sci. 75:1514-1520.

6. Schwartz, K.J., 1999. Salmonellosis. In: B.E. Straw, W.L. Mengeling, S. D'Allaire, and D.J. Taylor (Ed.) Diseases of Swine ( $7^{\text {th }}$ Ed.) p 570-583. Iowa State University Press, Ames IA.

7. Balaji, R., K.J. Wright, C.M. Hill, S.S. Dritz, E.L. Knoppel, and J.E. Minton, 2000. Acute phase responses of pigs challenged orally with Salmonella typhimurium. J. Anim. Sci. 78:18851891.

8. Mohn, S. and C.F.M. de Lange, 1998. The effect of body weight on the upper limit to protein deposition in a defined population of growing gilts. J. Anim. Sci. 76:124-133. 
9. CDC, 1997. Biosafety in Microbiological and Biomedical Laboratories. $3^{\text {rd }}$ Ed. Office of Health and Safety, Centers for Disease Control and Prevention. Available at: http://www.cdc.gov/od/ohs/biosfty/biosfty.htm Accessed Oct. 20, 1997.

10. AOAC, 1990. Official Methods of Analysis (15 ${ }^{\text {th }}$ Ed.). Association of Official Analytical Chemists, Arlington, VA.

11. Smith, J.E., P.S. Chavey, and G.A. Andrews, 1998. Semiautomatic and robotic methods for determining serum haptoglobin levels. Vet. Clin Path. 27:11-14.

12. Johnson, R.W., 1997. Inhibition of growth by proinflammatory cytokines: an integrated view. J. Anim. Sci. 75:1244-1255.

13. Mead, R., 1994. The Design of Experiments. Cambridge University Press, New York, NY.

14. Littell, R.C., G.A. Milliken, W.W. Stroup, and R.D. Wolfinger, 1996. SAS ${ }^{\circledR}$ System for Mixed Models. SAS Institute Inc., Cary, NC.

15. SAS, 1996. SAS/STAT ${ }^{\circledR}$ User's Guide (Release 6.12 Ed.). SAS Inst. Inc., Cary, NC.

16. Peterson, R.G., 1985. Design and Analysis of Experiments. Marcel Dekker, New York, NY.

17. Klasing, K.C., 1988. Nutritional aspects of leukocytic cytokines. J. Nutr. 118:1436-1446.

18. Cason, J., 1989. Immune reactions and host nutritional status: The role of interleukin-1. Nutr. Res. 9:237-250.

19. Dritz, S.S., K.Q. Owen, R.D. Goodband, J.L. Nelssen, M.D. Tokach, M.M. Chengappa, and F. Blecha, 1996. Influence of lipopolysaccharideinduced immune challenge and diet complexity on growth performance and acute-phase protein production in segregated early-weaned pigs. J. Anim. Sci. 74:1620-1628.

20. Turner, J.L., S.S. Dritz, J.J. Higgens, K.L. Herkelman and J.E. Minton, 2002. Effects of a Quillaja saponaria extract on growth performance and immune function of weanling pigs challenged with Salmonella typhimurium. J.Anim. Sci. 80:1939-1946.

21. Wright, K.J., B. Ramanathan, C.M. Hill, S.S. Dritz, E.L. Knoppel, and J.E. Minton, 2000. Integrated adrenal, somatrophic, and immune responses of growing pigs to treatment with lipopolysaccharide. J. Anim. Sci. 78:1892-1899.

22. Burkey, T.E., S.S. Dritz, J.C. Nietfeld, B.J. Johnson, and J E. Minton, 2004. Effects of dietary mannanoligosaccharide and sodium chlorate on the growth performance, actual phase response, and bacterial shedding of weaned pigs challenges with Salmonella enterica serotype Typhimurium, J. Anim. Sci. 82:397-404.
23. Loughmiller, J.A., S.S. Dritz, J.L. Nelssen, M.D. Tokach, R.D. Goodband, B.W. Fenwick, A. Weber, and T.L. McDonaldl 2005. Effects of Actinobacillus pleuropneumoniae challenge on growth, nitrogen balance, insulin-like growth factor-I, acute phase proteins and final body composition of swine. J. Anim. Vet. Adv. 4:805817.

24. Johnson, B.J., S.S. Dritz, K.A. Skjolaas-Wilson, T.E. Burkey, and J.E. Minton, 2005. Interactive responses in gut immunity, and systemic and local changes in the insulin-like growth factor system in nursery pigs in response to Salmonella enterica serovar Typhimurium. J. Anim. Sci. 83:E48-E56.

25. Morovat, A. and M.J. Dauncey, 1998. Effects of thyroid status on insulin-like growth factor-I, growth hormone and insulin are modified by food intake. Eur. J. Endocrinol. 138:95-103.

26. Buonomo, F.C., and C.A. Baile 1991. Influence of nutritional deprivation on insulin-like growth factor I, somatotropin, and metabolic hormones in swine. J. Anim. Sci. 69:755-760.

27. Klasing, K.C., D.E. Laurin, R.K. Peng, and D.M. Fry, 1987. Immunologically mediated growth depression in chicks: Influence of feed intake, corticosterone and interleukin-1. J. Nutr. 117:16291637.

28. van Heugten, E., M.T. Coffey, and J.W. Spears, 1996. Effects of immune challenge, dietary energy density, and source of energy on performance and immunity in weanling pigs. J. Anim. Sci. 74:24312440.

29. van Heugten, E., J.W. Spears, and M.T. Coffey, 1994. The effect of dietary protein on performance and immune response in weanling pigs subjected to an inflammatory challenge. J. Anim. Sci. 72:26612669.

29. Williams, N.H., T.S. Stahly, and D.R. Zimmerman, 1997b. Effect of chronic immune system activation on the rate, efficiency, and compostion of growth and lysine needs of pigs fed from 6 to $27 \mathrm{~kg}$. J. Anim. Sci. 75:2463-2471.

30. Hyun, Y., M. Ellis, G. Riskowski, and R.W. Johnson, 1998. Growth performance of pigs subjected to multiple concurrent environmental stressors. J. Anim. Sci. 76:721-727.

31. NRC, 1998. Nutrient requirements of swine $\left(10^{\text {th }}\right.$ Ed.). National Academy Press, Washington, DC.

32. Holck, J.T., A.P. Schinkel, J.L. Coleman, V.M. Wilt, M.K. Senn, B.J. Thacker, E.L. Thacker, and A.L. Grant, 1998. The influences of environment on the growth of commercial finisher pigs. Swine Health Prod. 6:141-149. 